\title{
Decitabine improves progression-free survival in older high-risk MDS patients with multiple autosomal monosomies: results of a subgroup analysis of the randomized phase III study 06011 of the EORTC Leukemia Cooperative Group and German MDS Study Group
}

\author{
Michael Lübbert ${ }^{1}$ - Stefan Suciu ${ }^{2}$ - Anne Hagemeijer ${ }^{3}$ - Björn Rüter ${ }^{1}$ • \\ Uwe Platzbecker $^{4}$ - Aristoteles Giagounidis ${ }^{5}$. Dominik Selleslag ${ }^{6}$ • Boris Labar ${ }^{7}$. \\ Ulrich Germing ${ }^{8}$ - Helmut R. Salih ${ }^{9}$ - Petra Muus ${ }^{10}$ - Karl-Heinz Pflüger ${ }^{11}$. \\ Hans-Eckart Schaefer ${ }^{12}$. Lioudmila Bogatyreva ${ }^{1,13}$. Carlo Aul ${ }^{14}$. Theo de Witte ${ }^{15}$. \\ Arnold Ganser $^{16}$ • Heiko Becker ${ }^{1}$. Gerwin Huls ${ }^{10,17}$ • Lieke van der Helm ${ }^{17}$. \\ Edo Vellenga ${ }^{17}$ • Frédéric Baron ${ }^{18}$ • Jean-Pierre Marie ${ }^{19}$ • Pierre W. Wijermans ${ }^{20}$. \\ on behalf of the EORTC Leukemia Group and the German MDS Study Group
}

Received: 21 October 2015 / Accepted: 1 November 2015 / Published online: 23 November 2015

(C) Springer-Verlag Berlin Heidelberg 2015

\begin{abstract}
In a study of elderly AML patients treated with the hypomethylating agent decitabine (DAC), we noted a surprisingly favorable outcome in the (usually very unfavorable) subgroup with two or more autosomal monosomies (MK2+)
\end{abstract}

within a complex karyotype (Lübbert et al., Haematologica 97:393-401, 2012). We now analyzed 206 myelodysplastic syndrome (MDS) patients ( $88 \%$ of 233 patients randomized in the EORTC/GMDSSG phase III trial 06011, 61 of them
Electronic supplementary material The online version of this article (doi:10.1007/s00277-015-2547-0) contains supplementary material, which is available to authorized users.

Michael Lübbert

michael.luebbert@uniklinik-freiburg.de

1 Division of Hematology, Oncology and Stem Cell Transplantation, University of Freiburg Medical Center, Freiburg, Germany

2 European Organisation for Research and Treatment of Cancer Headquarters, Brussels, Belgium

3 Department of Human Genetics, University Hospital, University of Leuven, Leuven, Belgium

4 Department of Hematology and Oncology, University of Dresden, Dresden, Germany

5 Department of Hematology and Oncology, Marienhospital, Düsseldorf, Germany

6 Department of Hematology, AZ Sint-Jan Brugge-Oostende, Brugge, Belgium

7 University Hospital Center Rebro, Zagreb, Croatia

8 Department of Hematology, Oncology and Clinical Immunology, Heinrich-Heine-University, Düsseldorf, Germany
Department of Hematology/Oncology, Eberhard Karls University, Tübingen, Germany

10 Department of Hematology, Radboud University Nijmegen Medical Centre, Nijmegen, The Netherlands

11 Department of Medicine II, DIAKO Bremen, Bremen, Germany

12 Institute of Pathology, University of Freiburg, Freiburg, Germany

13 Institute for Medical Biometry and Medical Informatics, University of Freiburg, Freiburg, Germany

14 Hematology, Oncology, and Clinical Immunology, St Johannes Hospital, Duisburg, Germany

15 Department of Tumor Immunology, Radboud University Nijmegen Medical Centre, Nijmegen, The Netherlands

16 Department of Hematology, Hemostasis, Oncology, and Stem Cell Transplantation, Hannover Medical School, Hannover, Germany

17 Department of Hematology, University Medical Center Groningen, Groningen, The Netherlands

18 C.H.U. Sart-Tilman, Liège, Belgium 
with RAEBt, i.e. AML by WHO) with cytogenetics informative for MK status.. Endpoints are the following: complete/ partial (CR/PR) and overall response rate (ORR) and progression-free (PFS) and overall survival (OS). Cytogenetic subgroups are the following: 63 cytogenetically normal $(\mathrm{CN})$ patients, 143 with cytogenetic abnormalities, 73 of them MKnegative (MK-), and $70 \mathrm{MK}-$ positive $(\mathrm{MK}+)$. These $\mathrm{MK}+$ patients could be divided into 17 with a single autosomal monosomy (MK1) and 53 with at least two monosomies (MK2+). ORR with DAC in CN patients: $36.1 \%$, in MKpatients: $16.7 \%$, in $\mathrm{MK}+$ patients: $43.6 \%$ (MK1: $44.4 \%$, MK2+ $43.3 \%$ ). PFS was prolonged by DAC compared to best supportive care (BSC) in the CN (hazard ratio (HR) $0.55,99 \%$ confidence interval $(\mathrm{CI}), 0.26 ; 1.15, p=0.03$ ) and MK2+ (HR 0.50; $99 \%$ CI, $0.23 ; 1.06, p=0.016)$ but not in the MK-, MK+, and MK1 subgroups. OS was not improved by DAC in any subgroup. In conclusion, we demonstrate for the first time in a randomized phase III trial that high-risk MDS patients with complex karyotypes harboring two or more autosomal monosomies attain encouraging responses and have improved PFS with DAC treatment compared to BSC.

Keywords Monosomal karyotype $\cdot$ Adverse cytogenetics Hypomethylating agents $\cdot$ Azacytidine $\cdot$ Epigenetic therapy . Elderly patients

\section{Introduction}

The treatment of elderly myelodysplastic syndrome (MDS)/AML patients with a complex karyotype still poses a highly unmet clinical need, given the low complete response rate and high relapse rate even after standard induction/consolidation chemotherapy or allogeneic transplantation. Regarding non-curative AML treatment of older patients in the randomized MRC trial AML14, comparing low-dose cytarabine to best supportive care (BSC), patients with adverse cytogenetics (the majority with complex karyotypes) had an equally dismal outcome in both treatment arms, with a median survival of less than 2 months and a 1 -year survival below $5 \%$ [1]. Not surprisingly, a complex karyotype thus scores in the very highrisk cytogenetic groups of AML and MDS [2-5]. Notably, it recently became apparent that clofarabine and the DNA hypomethylating agents azacytidine and decitabine (DAC) have marked activity in complex-karyotype AML [6-9]

19 UPMC, UMRS 872 and Saint-Antoine Hospital, AP-HP, Paris, France

20 Department of Hematology, Haga Hospital, The Hague, The Netherlands and MDS [10-16]. However, it is unclear why these drugs differ from cytarabine and other cytotoxic agents in that regard. Equally notable was the recurrent observation of activity of DAC [13, 15-18] and azacytidine [10, 19] in MDS/AML patients with sole monosomy 7-also a robust clinical result but as yet lacking a mechanistic explanation. A monosomy might be only one of several abnormalities and may not exhibit prognostic impact itself [20,21].

We therefore recently hypothesized that AML patients with complex karyotype $(\mathrm{CK}+)$ including one or more autosomal monosomies $(\mathrm{MK}+$, most frequently monosomy 7) might show a response to hypomethylating agent treatment that is absent in complex-karyotype patients without autosomal monosomies ( $\mathrm{MK}-/ \mathrm{CK}+)$. Since the large phase II DAC trial 00331 had recruited $54 \mathrm{CK}+$ patients, their outcome was compared with regard to the presence $(\mathrm{MK}+/$ $\mathrm{CK}+, n=37)$ or absence $(\mathrm{MK}-/ \mathrm{CK}+, n=17)$ of the monosomal karyotype [8]. Intriguingly, the response rate was superior in the $\mathrm{MK}+/ \mathrm{CK}+\mathrm{AML}$ patients compared to $\mathrm{MK}-/ \mathrm{CK}+$ patients (complete plus partial remissions 37 vs. $12 \%$ ). Seemingly paradoxical was the result in the group of 22 patients with at least two monosomies (MK2+): these patients showed a $45 \%$ complete remission $(\mathrm{CR}) /$ partial remission (PR) rate vs. $25 \%$ in the 15 patients with a single monosomy (MK1) [8].

To extend this observation (collected from a single AML trial) also to higher-risk MDS, we now conducted identical cytogenetic subgroup analyses on 206 higherrisk MDS patients (FAB classification) with informative cytogenetics included in the randomized phase III trial 06011 of the EORTC Leukemia Group and the German MDS Study Group [11] (constituting, after the recent report of a subgroup analysis of the RAEBt patients [22], the second subgroup analysis from this study; for a listing of the Study Consortium see Supplementary Information). We also provide supportive evidence from 118 additional higher-risk MDS patients from two phase II DAC trials [13].

Key findings are a comparable rate of overall and objective responses to $\mathrm{DAC}$ in the normal karyotype and $\mathrm{MK}+$ patients, and prolonged progression-free (though not overall) survival in patients with complex karyotype and two or more autosomal monosomies treated with DAC compared to best supportive care. The in vivo mechanism of action of DAC in these patients may be distinct from standard chemotherapy such as low-dose AraC.

\section{Patients and methods}

Patients were eligible for the EORTC Leukemia Cooperative Group phase III trial 06011 [11] if aged $\geq 60$ years and diagnosed with primary or treatment-related MDS or chronic 
myelomonocytic leukemia $(\mathrm{CMMoL})$ irrespective of white blood counts; IPSS intermediate-1, IPSS intermediate-2, or high; bone marrow blasts $11-30 \%$; or $\leq 10 \%$ but with poor cytogenetics (IPSS) and ECOG performance status $0-2$. Severe cardiovascular disease was an exclusion criterion, whereas previous treatment of MDS was not (except aggressive chemotherapy or treatment with a hypomethylating agent). The study was performed in accordance with the Declaration of Helsinki, all patients provided written informed consent, and the study was approved by the local ethics committees at all participating trial sites. The definition of monosomal karyotype was as by Breems et al. [23], i.e., at least two autosomal monosomies or one single autosomal monosomy in combination with at least one structural abnormality.

\section{Statistical analysis}

Responses were assessed according to the International Working Group criteria [24, 25], with sequential bone marrow studies planned after every other course of decitabine and at weeks 24 and 48 for patients on the BSC arm, earlier in both arms in case of suspected progression. Before and during the study, evaluations of bone marrow aspirates were performed locally by the investigators.

Progression-free survival (PFS) was defined as time from random assignment to progression, relapse after attainment of complete remission (CR) or partial response (PR), or death, whichever occurred first. Overall survival (OS) was defined as time from randomization until death (whatever the cause) or the last follow-up (censored observation). The Kaplan-Meier method was used to estimate PFS and OS. The two-sided, log-rank test was used for comparisons of treatment outcome. The Cox proportional hazards model was used to obtain hazard ratio (HR) estimates and corresponding confidence intervals (CIs). Subgroup analyses were performed using forest plot techniques. For efficacy analyses, the intent-to-treat principle was followed.

\section{Results}

\section{EORTC/GMDSSG randomized phase III trial 06011: frequent recruitment of MDS patients with monosomal karyotype}

Of 233 patients randomized to either DAC or BSC, 206 had cytogenetic analyses allowing evaluation for the absence or presence of a monosomal karyotype (MK; CONSORT information: Table 1, clinical characteristics: Table 2). For the remaining 27 patients, cytogenetic scoring for MK status was not feasible. As shown in
Table 1 CONSORT diagram (06011 phase III trial, 206 patients with informative karyotypes)

\begin{tabular}{lll}
\hline & $n=206$ patients & \\
\cline { 2 - 3 } & $\begin{array}{l}\text { Treatment arm: supportive } \\
\text { care }(N=101) \\
n(\%)\end{array}$ & $\begin{array}{l}\text { Treatment arm: } \\
\text { decitabine }(N=105) \\
n(\%)\end{array}$ \\
\hline Reason off-protocol & & \\
Normal completion & $18(17.8)$ & $26(24.8)$ \\
PD & $49(48.5)$ & $36(34.3)$ \\
Toxicity & $0(0.0)$ & $19(18.1)$ \\
Hypoplasia & $0(0.0)$ & $5(4.8)$ \\
Death & $15(14.9)$ & $10(9.5)$ \\
Refusal & $12(11.9)$ & $3(2.9)$ \\
Protocol violation & $4(4.0)$ & $3(2.9)$ \\
Ineligibility & $1(1.0)$ & $1(1.0)$ \\
Other & $2(2.0)$ & $2(1.9)$ \\
\hline
\end{tabular}

Table 3, 63 of the 206 patients were cytogenetically normal $(\mathrm{CN})$, and 143 had cytogenetic abnormalities (CA). These CA patients can be subdivided into those without (MK-, $n=73)$ and with $\mathrm{MK}(\mathrm{MK}+, n=70)$. Of the $\mathrm{MK}-$ patients, 54 had one or two cytogenetic abnormalities (i.e., "non-complex," $\mathrm{MK}-/ \mathrm{CK}-$ ), and 18 had a complex karyotype $(\mathrm{MK}-/ \mathrm{CK}+)$. Among the $\mathrm{MK}+$ patients, four scored as $\mathrm{CK}-$, the remaining 66 patients as $\mathrm{CK}+$. Overall, this patient cohort has a strong representation of very high-risk cytogenetic patients.

\section{DAC induces objective responses in all cytogenetic subgroups including complex karyotypes with multiple monosomies}

Among all 206 patients with cytogenetics informative for $\mathrm{MK}$, the overall response rate (ORR, complete and partial remissions, hematological improvement) was $33.3 \%$ in the 105 patients on the DAC arm vs. $2 \%$ on the BSC arm (two patients had hematological improvement), making comparisons between the two treatment arms not very meaningful (Table 3). We therefore focused on the ORR in the different cytogenetic subgroups of the DAC arm. The $36 \mathrm{CN}$ patients had a $36.1 \%$ ORR, and the $69 \mathrm{CA}$ patients had a $31.9 \%$ ORR. When next looking to the CA patients without $\mathrm{MK}(\mathrm{MK}-, n=$ 30 ), an ORR of $16.7 \%$ was seen, in the CA patients with MK $(\mathrm{MK}+, n=39)$ an ORR of $43.6 \%$. Notably, this response rate was comparable between patients with one (MK1, $n=9$, $44.4 \%$ ) and two or more monosomies (MK2+, $n=30$, $43.3 \%$ ), the latter generally being considered the cytogenetic subgroup with the most adverse prognosis. 
Table 2 Patient baseline characteristics (all patients, $n=$ 233; patients informative for monosomal karyotype, $n=206$ )

\begin{tabular}{|c|c|c|c|c|}
\hline \multirow[t]{2}{*}{ Baseline characteristics } & \multicolumn{2}{|c|}{ Patients total $(n=233)$} & \multicolumn{2}{|c|}{$\begin{array}{l}\text { Patients informative for monosomal karyotype } \\
(n=206)\end{array}$} \\
\hline & DAC $n=119$ & $\mathrm{BSC} n=114$ & DAC $n=105$ & $\mathrm{BSC} n=101$ \\
\hline Age, median (range) & $69(60 ; 90)$ & $70(60 ; 86)$ & $69(60 ; 90)$ & $70(60 ; 86)$ \\
\hline$>=75$ years, $n(\%)$ & $33(27.7)$ & $34(29.8)$ & $28(26.7)$ & $31(30.7)$ \\
\hline \multicolumn{5}{|l|}{ Sex, $n(\%)$} \\
\hline Male & $76(63.9)$ & $73(64)$ & $65(61.9)$ & $62(61.4)$ \\
\hline \multicolumn{5}{|l|}{$\mathrm{FAB}, n(\%)$} \\
\hline RA/RARS & $8(6.7)$ & $10(8.8)$ & $9(8.5)$ & $10(9.9)$ \\
\hline RAEB & $61(51.3)$ & $64(56.1)$ & $52(49.5)$ & $59(58.4)$ \\
\hline RAEBt & $40(33.6)$ & $35(30.7)$ & $34(32.4)$ & $27(26.7)$ \\
\hline AML & $1(0.8)$ & $1(0.9)$ & $1(1.0)$ & $1(1.0)$ \\
\hline CMMoL & $10(8.4)$ & $4(3.5)$ & $9(8.6)$ & $4(4.0)$ \\
\hline \multicolumn{5}{|l|}{ IPSS, $n(\%)$} \\
\hline Low & - & - & - & - \\
\hline Int 1 & $8(6.7)$ & $8(7.0)$ & $5(4.8)$ & $8(7.9)$ \\
\hline Int 2 & $64(53.8)$ & $63(55.3)$ & $55(52.4)$ & $52(51.5)$ \\
\hline High & $46(38.7)$ & $42(36.8)$ & $45(42.9)$ & $41(40.6)$ \\
\hline
\end{tabular}

Considering that these results might be skewed by a lower rate of objective responses (CR, PR) and a higher rate of hematological improvement in the cytogenetically less favorable compared to the cytogenetically more favorable subgroups, we next looked to the CR/PR rate. Here in the CN group, three and four patients had a CR or PR, respectively $(19.4 \%)$; there were four CRs in the MK- group (13.3\%) and seven CRs and two PRs in the MK+ group $(23.0 \%)$. When dividing the $\mathrm{MK}+$ group into MK1 and $\mathrm{MK} 2+$, the respective $\mathrm{CR} / \mathrm{PR}$ rates were 44.4 and $16.7 \%$.

Further support for the ability of DAC to induce objective responses also in $\mathrm{MK}+$ patients is provided by a retrospective cytogenetic analysis we now performed of two phase II trials of DAC in MDS [13]. One hundred eighteen of the 143 patients were informative for MK status (Supplementary Table 1A). Here, the ORR was $48.3 \%$ in the entire cohort, $46.7 \%$ in the $\mathrm{CN}$ group, $46.6 \%$ in the $\mathrm{MK}-$ group, and $60.0 \%$ in the MK+ group (MK1, $66.7 \%$; MK2+, $58.3 \%$, see Supplementary Table 1B).

\section{Outcome with DAC vs. best supportive care in MDS patients in different cytogenetic subgroups}

To next address possible interactions between treatment and cytogenetic subgroups, we looked to PFS and OS. For the entire study cohort of the trial (233 patients) [11], for the 206 patients informative for MK status (Table 3), and for the 27 patients with unknown MK status (Supplementary Figure 1), PFS but not overall survival (OS) was sensitive enough to detect a significant effect of DAC treatment compared to BSC.

When looking to the different cytogenetic groups, the $\mathrm{CN}$ patients treated with DAC had a prolonged PFS (HR 0.55 $[0.26 ; 1.15], p=0.03)$ but not OS compared to patients receiving sole BSC (Table 3, Figs. 1 and 2a, b). Among the 143 patients with any cytogenetic abnormalities, this difference in PFS was not so impressive and did not reach statistical significance (HR $0.76[0.49 ; 1.18], p=0.11$ ). There was no difference in OS.

When dividing this group into MK $-(n=73)$ and $\mathrm{MK}+(n=$ 70), we first looked to the MK- patients: their median PFS was 0.36 years with DAC treatment vs. 0.26 years with BSC (HR $0.81[0.43 ; 1.55], p=0.41$ ). Median OS was 0.63 years in $\mathrm{MK}-$ patients receiving DAC vs. 0.68 years in those receiving BSC (HR 0.98 [0.49; 1.97], $p=0.93$ ), as shown in Table 3 and Fig. $1 b$.

When dividing this $\mathrm{MK}-$ group into patients without or with complex karyotype (CK), in the $54 \mathrm{MK}-/ \mathrm{CK}$ - patients, there seemed to be a trend towards longer PFS with DAC treatment compared to BSC (HR $0.70[0.33 ; 1.48], p=0.22$ ) that was not apparent in the $18 \mathrm{MK}-/ \mathrm{CK}+$ patients (HR 0.95 $[0.26 ; 3.49], p=0.92)$. However, it should be stressed that such trend may also be due to the increasingly smaller patient group sizes when conducting such comparisons. In both subgroups, OS was similar between treatment arms (Table 3).

Among the $70 \mathrm{MK}+$ patients, by trend, DAC also seemed to have a positive effect on PFS (median 0.47 years) when compared to BSC (median 0.21 years; HR 0.73 [0.38; 1.38], $p=0.20$ ). Here also, the OS was similar between the two treatment modalities (HR $0.93[0.49 ; 1.75], p=0.76$ ). 
MDS patients with a complex karyotype harboring two or more autosomal monosomies have longer progression-free but not overall survival with DAC compared to best supportive care

It is generally accepted that patients with AML/MDS and more than a single autosomal monosomy have an inferior outcome than those with MK1 when treated with standard chemotherapy. We first subdivided the $70 \mathrm{MK}+$ into those with one and two more monosomies, i.e., MK1 $(n=17)$ and MK2+ $(n=53)$, respectively. As shown in Table 3, PFS in the MK1 subgroup ( $n=17$, four of them not fulfilling CK criteria) was similar in both treatment arms (HR 0.88 [0.24; 3.24], $p=$ 0.81 ), as was overall survival. Interestingly, median PFS of the $30 \mathrm{MK} 2+$ patients treated with DAC was 0.45 years; compared to 0.18 years in the $23 \mathrm{MK} 2+$ patients treated with BSC (Table 3, Fig. 2c), the resultant HR was 0.50 (0.23; $1.05], p=0.016)$. OS was not different between the two treatment groups (Fig. 2d; HR 0.99 [0.47; 2.92], $p=0.98$, Table 3; see also Fig. 2d).

\section{Discussion}

Already in 1997, Wijermans et al. [26] noted the ability of DAC to induce remissions in MDS patients with complex karyotype and other adverse cytogenetics. This - at first counterintuitive - clinical finding was confirmed in MDS [27, 28] and AML $[7,8]$. While these trials were ongoing, Breems et al. [23] first described the novel cytogenetic poor-risk category of MK in AML. This genotype is clinically distinct: the presence of one or more autosomal monosomies imbedded in a complex karyotype was associated with a worse prognosis than a complex karyotype without a monosomy. The presence of two or more autosomal monosomies increases the negative prognostic compared to a single monosomy impact, as shown in several large AML and MDS patient series (standard chemotherapy, allografting).

In order to confirm the intriguing response rates and overall survival of MK AML patients observed in the 00331 trial, we now analyzed MDS patients of the 06011 EORTC trial. Asking whether overall (ORR: $\mathrm{CR} / \mathrm{PR} / \mathrm{HI}$ ) and objective response rates $(\mathrm{CR} / \mathrm{PR})$ differed between these groups, we found that for both, the $\mathrm{MK}+$ patients had response rates comparable to the $\mathrm{CN}$ group (cytogenetically low risk by IPSS). This encouraging finding is supported by a retrospective analysis of 118 higher-risk MDS patients for response by MK status treated on two previous phase II DAC trials. We also had the chance to cytogenetically analyze a large cohort of MDS patients (mostly IPSS int-2/high) treated within a Dutch namedpatient azacytidine program (for patient characteristics see Supplementary Table 2A). While it is difficult to compare response rates between a randomized trial and a treatment 


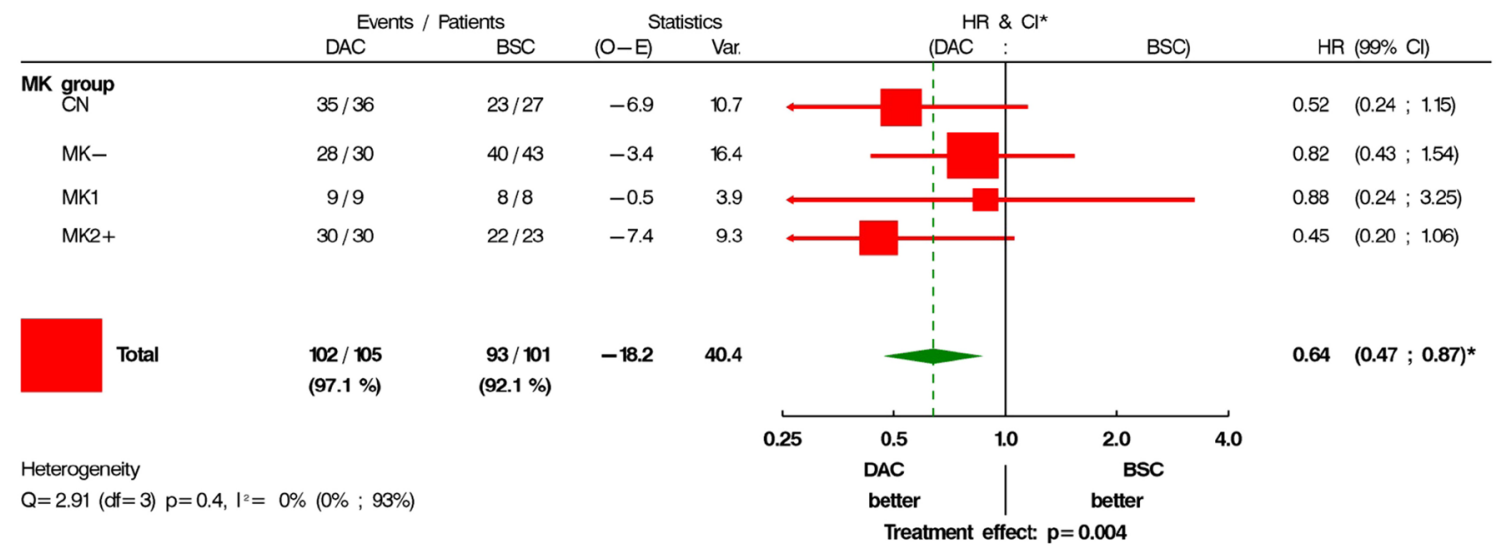

$\star 95 \% \mathrm{Cl}$ for totals and subtotals, $99 \% \mathrm{Cl}$ elsewhere

b

06011: Survival

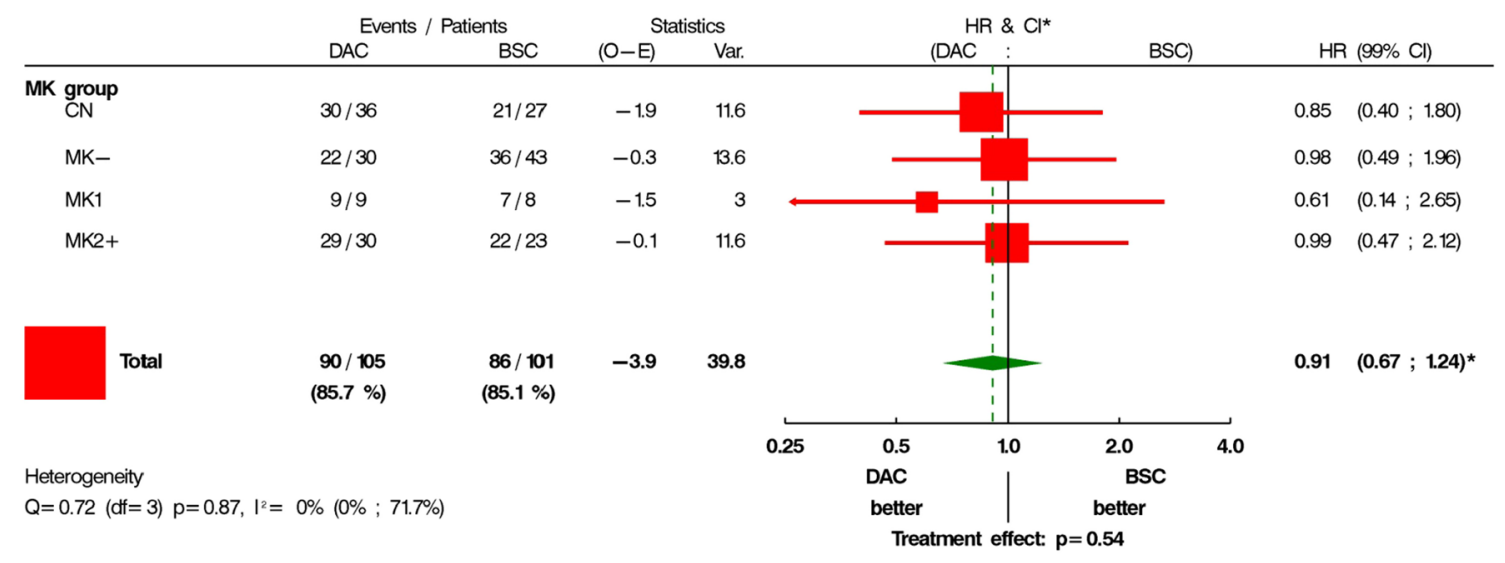

${ }^{*} 95 \% \mathrm{Cl}$ for totals and subtotals, $99 \% \mathrm{Cl}$ elsewhere

Fig. 1 Forest plots depicting a progression-free and $\mathbf{b}$ overall survival of the different cytogenetic subgroups in the 06011 phase III trial by random assignment. Patients with informative karyotype with normal cytogenetics $(C N)$ and abnormal cytogenetics without monosomal karyotype $\left(M K^{-}\right)$and with one (MK1) or two or more (MK2+)

program, when looking to ORR and CR/PR, some of the 26 $\mathrm{MK}+$ patients treated with azacytidine also responded to this hypomethylating agent, even in the MK2+ subgroup $(n=17$, $29.4 \%$ ORR, $17.6 \%$ CR/PR, Supplementary Table 2B). A summarical tabulation of the outcome of all 319 DAC-treated patients from the three data sets analyzed is provided in Supplementary Table 3.

When analyzing the 06011 cohort for progression-free and overall survival in the different cytogenetic subgroups monosomies were analyzed. $D A C$ decitabine, $B S C$ best supportive care, $O$ observed, $E$ expected, Var variance, $C I$ confidence interval, $H R$ hazard ratio $99 \%$ CIs. Parentheses with asterisk indicate $95 \%$ CIs for totals and subtotals

according to treatment arm, only the $\mathrm{CN}$ patients and those with MK2+ (the two "extremes" within the prognostic spectrum) treated with DAC had prolonged PFS compared to those on the BSC arm; for the other cytogenetic subgroups, median PFS appeared similar. Overall survival was not prolonged by DAC treatment, and possible reasons have been discussed [11]. Briefly, four major factors could be identified: (i) suboptimal DAC dose and schedule (3day dosing repeated every 6 weeks); (ii) DAC treatment 
a

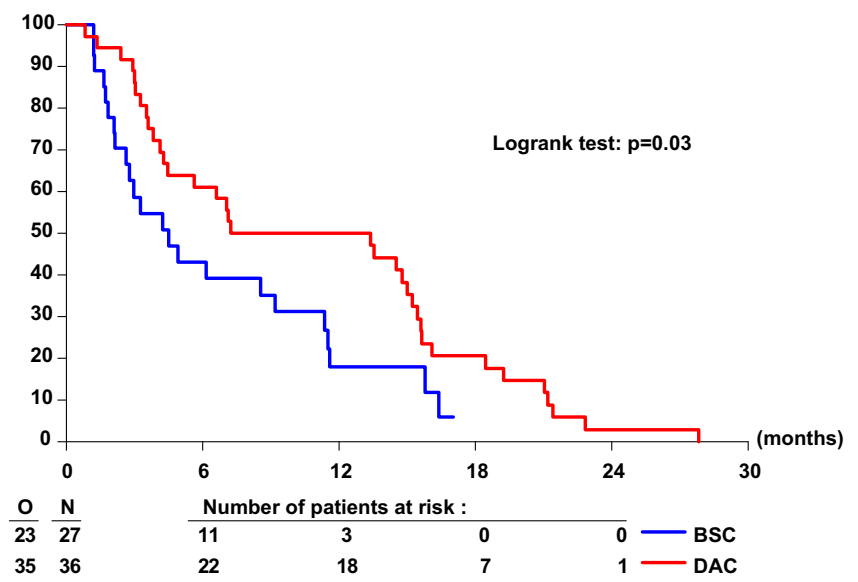

b

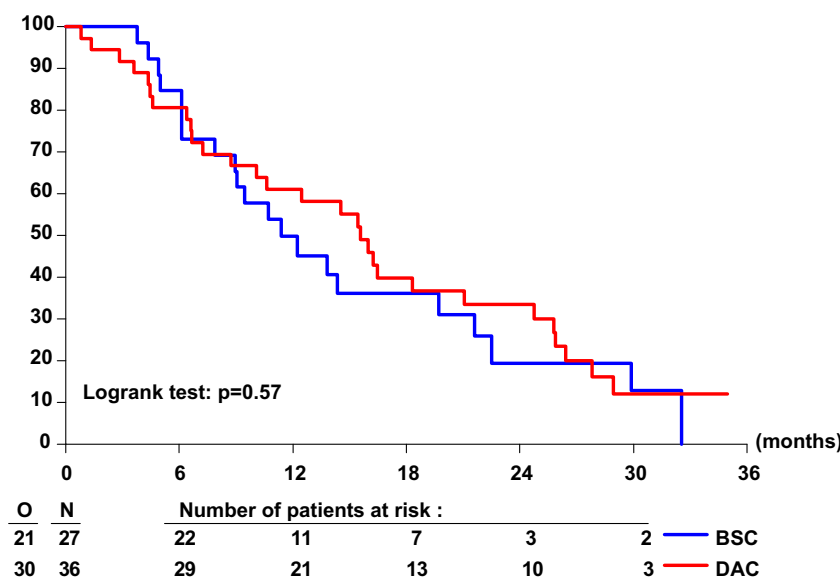

Fig. 2 Progression-free $(\mathbf{a}, \mathbf{c})$ and overall survival $(\mathbf{b}, \mathbf{d})$ of patients of the 06011 phase III trial with normal karyotype (a, b) and MK2+ karyotype (c, d) depicted by Kaplan-Meier plot according to treatment arm. Note that two MK2+ patients receiving sole best supportive care (c) also lived without progression of their MDS beyond 18 months. $O$ observed events,

duration limited to 8 cycles (10 in CR patients); (iii) patient disposition, with a median duration from MDS diagnosis to randomization of only 3 months; and (iv) postprogression treatment as a confounder. It would be of interest to apply the specific scoring system recently described by Oosterveld et al. for AML/MDS patients treated with standard chemotherapy, in which poor cytogenetics predicted inferior survival [29].

Thus far, only very few studies have specifically addressed the role of MK in hypomethylating agent (HMA) treatment. The largest azacytidine studies describe either a similar overall survival of MDS patients with $\mathrm{CK}+\mathrm{MK}+$ or $\mathrm{CK}+/ \mathrm{MK}-[30]$ or a worse outcome of AML patients with $\mathrm{CK}+/ \mathrm{MK}+$ compared to $\mathrm{CK}+/ \mathrm{MK}-$ [31], albeit with limited patient numbers. Our post hoc analysis constitutes the first analysis of a phase III randomized HMA trial in MDS/ AML, but it has similar limitations: when comparing
C

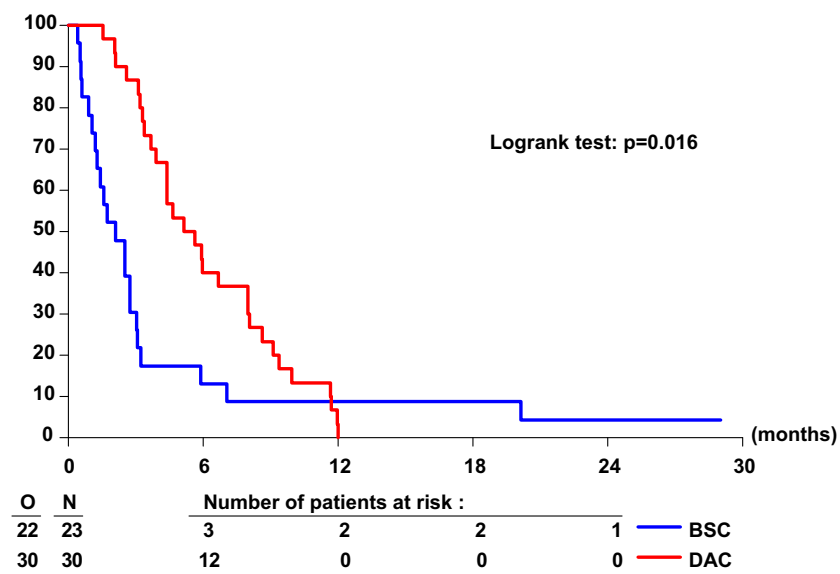

d

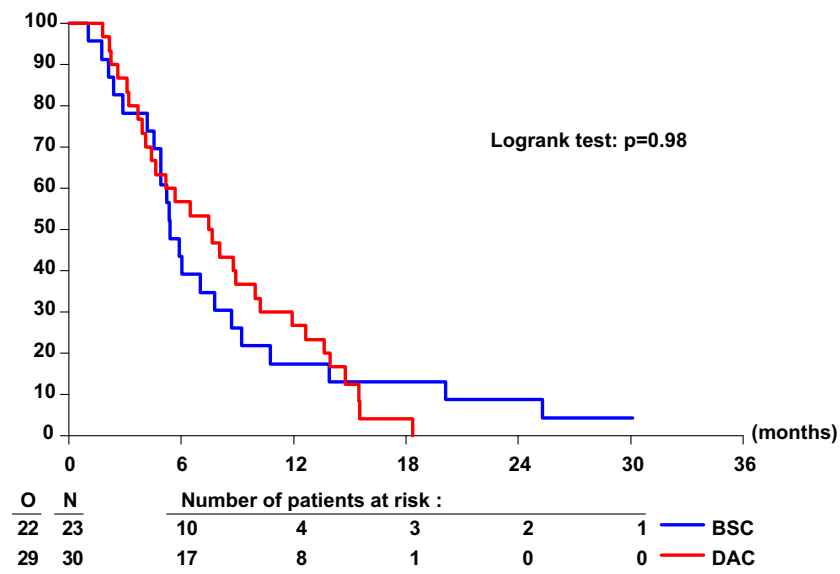

$N$ patients, $B S C$ treatment arm best supportive care, $D A C$ treatment arm DAC. a Progression-free survival in cytogenetically normal patients. b Overall survival in cytogenetically normal patients. c Progression-free survival in MK2+ patients. d Overall survival in MK2+ patients

cytogenetic subgroups of DAC-treated patients, the numbers (particularly in the $\mathrm{CK}+/ \mathrm{MK}$ - group, $n=9$ ) became too small to allow meaningful comparisons of outcomes. In that regard, the test for interaction indicated in Fig. 1a was not significant. However, the power of such a test is very low given the limited number of patients (and events) analyzed. Therefore, even if an interaction between MK status and the treatment difference is observed, it cannot reach statistical significance. If, however, several studies report the same trend, it will become significant in a meta-analysis.

Collectively, our results provide further evidence that DAC has encouraging activity in MDS/AML patients with a complex karyotype including multiple monosomies. It is tempting to speculate that this is mechanistically linked to the DNA hypomethylating and gene-derepressive activity of this agent. In future MDS/AML trials with HMAs, outcome by MK status should be prospectively captured. 
Acknowledgments The authors thank Philipp Sander and Margit Sauer for the editorial assistance and Claudia Schmoor for the helpful discussions. This publication was supported by the EORTC Charitable Trust; the 06011 trial was supported by an educational grant from MGI Pharma and Janssen Research and Development. Survival data of the PCH phase II studies were kindly provided by Janssen Research and Development. M.L. is supported by DFG (SFB 992/Medep).

Authors' contributions M.L., S. S., A. H., B. R., P. M., L. B., G. H., T. de W., and P. W. W. contributed to the conception and design. M. L., B. R., U. P., A. G., D. S., U. G., B. L, K.-H. P., H.-E. Sch., H. R. S., P. M., G. H., L. van der H., E. V., F. B., J.-P. M., A. G., C. A., T. de W., and P. W. W. contributed to the provision of study materials or patients. M.L., S. S., A. H., L. van der H., and G. H. contributed to the collection and assembly of data. M.L., S. S., and L. B. contributed to the data analyses and interpretation. M.L., S.S., and L. B. contributed to the manuscript writing. All authors have read and approved the final manuscript.

\section{Compliance with ethical standards}

Conflict of interest The authors declare no competing financial conflict of interests except for the following authors (U, no compensation was received; C, compensation was received): Consultant or Advisory Role: Uwe Platzbecker, Celgene (C), Amgen (C), and Novartis (C); Aristoteles Giagounidis, Celgene (C); Dominik Selleslag, Celgene (C), Novartis (C), and Amgen (C); Arnold Ganser, Celgene (C) and Novartis (C); and Michael Lübbert, Johnson \& Johnson (C); and Petra Muus, Alexion (U). Honoraria: Uwe Platzbecker, Celgene, Novartis, and Amgen; Aristoteles Giagounidis, Celgene; Dominik Selleslag, Celgene, Novartis, and Amgen; Ulrich Germing, Johnson \& Johnson; and Arnold Ganser, Genzyme. Research Funding: Michael Lübbert, Johnson \& Johnson; Uwe Platzbecker, Celgene and Novartis; and Ulrich Germing, MDS Registry Düsseldorf.

\section{References}

1. Burnett AK, Milligan D, Prentice AG, Goldstone AH, McMullin MF, Hills RK, Wheatley K (2007) A comparison of low-dose cytarabine and hydroxyurea with or without all-trans retinoic acid for acute myeloid leukemia and high-risk myelodysplastic syndrome in patients not considered fit for intensive treatment. Cancer 109(6):1114-1124. doi:10.1002/cncr.22496

2. Greenberg PL, Tuechler H, Schanz J, Sanz G, Garcia-Manero G, Sole F, Bennett JM, Bowen D, Fenaux P, Dreyfus F, Kantarjian H, Kuendgen A, Levis A, Malcovati L, Cazzola M, Cermak J, Fonatsch C, Le Beau MM, Slovak ML, Krieger O, Lubbert M, Maciejewski J, Magalhaes SMM, Miyazaki Y, Pfeilstöcker M, Sekeres M, Sperr WR, Stauder R, Tauro S, Valent P, Vallespi T, van de Loosdrecht AA, Germing U, Haase D (2012) Revised international prognostic scoring system for myelodysplastic syndromes. Blood 120(12):2454-2465. doi:10.1182/blood-2012-03-420489

3. Haase D, Germing U, Schanz J, Pfeilstöcker M, Nösslinger T, Hildebrandt B, Kündgen A, Lübbert M, Kunzmann R, Giagounidis AAN, Aul C, Trümper L, Krieger O, Stauder R, Müller TH, Wimazal F, Valent P, Fonatsch C, Steidl C (2007) New insights into the prognostic impact of the karyotype in MDS and correlation with subtypes: evidence from a core dataset of 2124 patients. Blood 110(13):43854395. doi:10.1182/blood-2007-03-082404

4. Kayser S, Zucknick M, Döhner K, Krauter J, Köhne CH, Horst HA, Held G, von Lilienfeld-Toal M, Wilhelm S, Rummel M, Germing U, Götze K, Nachbaur D, Schlegelberger B, Göhring G, Späth D,
Morlok C, Teleanu V, Ganser A, Döhner H, Schlenk RF (2011) Monosomal karyotype in adult acute myeloid leukemia: prognostic impact and outcome after different treatment strategies. Blood 119(2):551-558. doi:10.1182/blood-2011-07-367508

5. Döhner H, Estey EH, Amadori S, Appelbaum FR, Büchner T, Burnett AK, Dombret H, Fenaux P, Grimwade D, Larson RA, Lo-Coco F, Naoe T, Niederwieser D, Ossenkoppele GJ, Sanz MA, Sierra J, Tallman MS, Löwenberg B, Bloomfield CD (2009) Diagnosis and management of acute myeloid leukemia in adults: recommendations from an international expert panel, on behalf of the European leukemiaNet. Blood 115(3):453-474. doi:10.1182/ blood-2009-07-235358

6. Burnett AK, Russell NH, Kell J, Dennis M, Milligan D, Paolini S, Yin J, Culligan D, Johnston P, Murphy J, McMullin MF, Hunter A, Das-Gupta E, Clark R, Carr R, Hills RK (2010) European development of clofarabine as treatment for older patients with acute myeloid leukemia considered unsuitable for intensive chemotherapy. J Clin Oncol 28(14):2389-2395. doi:10.1200/jco.2009.26.4242

7. Cashen AF, Schiller GJ, O'Donnell MR, DiPersio JF (2009) Multicenter, phase II study of decitabine for the first-line treatment of older patients with acute myeloid leukemia. J Clin Oncol 28(4): 556-561. doi:10.1200/jco.2009.23.9178

8. Lübbert M, Rüter BH, Claus R, Schmoor C, Schmid M, Germing U, Kuendgen A, Rethwisch V, Ganser A, Platzbecker U, Galm O, Brugger W, Heil G, Hackanson B, Deschler B, Döhner K, Hagemeijer A, Wijermans PW, Döhner H (2012) A multicenter phase II trial of decitabine as first-line treatment for older patients with acute myeloid leukemia judged unfit for induction chemotherapy. Haematologica 97(3):393-401. doi:10.3324/haematol.2011. 048231

9. Dombret H, Seymour JF, Butrym A, Wierzbowska A, Selleslag D, Jang JH, Kumar R, Cavenagh J, Schuh AC, Candoni A, Récher C, Sandhu I, Bernal Del Castillo T, Al-Ali HK, Martinelli G, Falantes J, Noppeney R, Stone RM, Minden MD, McIntyre H, Songer S, Lucy LM, Beach CL, Döhner H (2015) International phase 3 study of azacitidine vs conventional care regimens in older patients with newly diagnosed AML with $>30 \%$ blasts. Blood 126(3):291-299. doi:10.1182/blood-2015-01-621664

10. Fenaux P, Mufti GJ, Hellström-Lindberg E, Santini V, Finelli C, Giagounidis A, Schoch R, Gattermann N, Sanz G, List A, Gore SD, Seymour JF, Bennett JM, Byrd J, Backstrom J, Zimmerman L, McKenzie D, Beach CL, Silverman LR (2009) Efficacy of azacitidine compared with that of conventional care regimens in the treatment of higher-risk myelodysplastic syndromes: a randomised, open-label, phase III study. Lancet Oncol 10(3):223232. doi:10.1016/s1470-2045(09)70003-8

11. Lübbert M, Suciu S, Baila L, Rüter BH, Platzbecker U, Giagounidis A, Selleslag D, Labar B, Germing U, Salih HR, Beeldens F, Muus P, Pflüger KH, Coens C, Hagemeijer A, Schaefer HE, Ganser A, Aul C, de Witte T, Wijermans PW (2011) Low-dose decitabine versus best supportive care in elderly patients with Intermediate- or highrisk myelodysplastic syndrome (MDS) ineligible for intensive chemotherapy: final results of the randomized phase III study of the European organisation for research and treatment of cancer leukemia group and the German MDS study group. J Clin Oncol 29(15): 1987-1996. doi:10.1200/jco.2010.30.9245

12. van der Helm LH, Alhan C, Wijermans PW, van Marwijk KM, Schaafsma R, Biemond BJ, Beeker A, Hoogendoorn M, van Rees BP, de Weerdt O, Wegman J, Libourel WJ, Luykx-de Bakker SA, Minnema MC, Brouwer RE, Croon-de Boer F, Eefting M, Jie KSG, van de Loosdrecht AA, Koedam J, Veeger NJGM, Vellenga E, Huls G (2011) Platelet doubling after the first azacitidine cycle is a promising predictor for response in myelodysplastic syndromes (MDS), chronic myelomonocytic leukaemia (CMML) and acute myeloid leukaemia (AML) patients in the Dutch azacitidine 
compassionate named patient programme. $\mathrm{Br} \mathrm{J}$ Haematol 155(5): 599-606. doi:10.1111/j.1365-2141.2011.08893.x

13. Wijermans PW, Lübbert M, Verhoef G, Klimek V, Bosly A (2005) An epigenetic approach to the treatment of advanced MDS; the experience with the DNA demethylating agent 5-aza-2'deoxycytidine (decitabine) in 177 patients. Ann Hematol 84(S1): 9-17. doi:10.1007/s00277-005-0012-1

14. van der Helm LH, Veeger NJGM, Kooy MM, Beeker A, de Weerdt O, de Groot M, Alhan C, Hoogendoorn M, Laterveer L, van de Loosdrecht AA, Koedam J, Vellenga E, Huls G (2013) Azacitidine results in comparable outcome in newly diagnosed AML patients with more or less than $30 \%$ bone marrow blasts. Leuk Res 37(8):877-882. doi:10.1016/j.leukres.2013.03.022

15. Jabbour E, Garcia-Manero G, Ravandi F, Faderl S, O'Brien S, Fullmer A, Cortes JE, Wierda W, Kantarjian H (2013) Prognostic factors associated with disease progression and overall survival in patients with myelodysplastic syndromes treated with decitabine. Clin Lymphoma Myeloma Leuk 13(2):131-138. doi:10.1016/j. clml.2012.11.001

16. Estey EH (2013) Epigenetics in clinical practice: the examples of azacitidine and decitabine in myelodysplasia and acute myeloid leukemia. Leukemia 27(9):1803-1812. doi:10.1038/leu.2013.173

17. Lübbert M, Wijermans P, Kunzmann R, Verhoef G, Bosly A, Ravoet C, Andre M, Ferrant A (2001) Cytogenetic responses in high-risk myelodysplastic syndrome following low-dose treatment with the DNA methylation inhibitor 5-aza-2'-deoxycytidine. Br J Haematol 114(2):349-357. doi:10.1111/j.1365-2141.2001.02933.x

18. Rüter B, Wijermans P, Claus R, Kunzmann R, Lübbert M (2007) Preferential cytogenetic response to continuous intravenous lowdose decitabine (DAC) administration in myelodysplastic syndrome with monosomy 7. Blood 110(3):1080-1082. doi:10.1182/ blood-2007-03-080630

19. Raj K, John A, Ho A, Chronis C, Khan S, Samuel J, Pomplun S, Thomas NSB, Mufti GJ (2007) CDKN2B methylation status and isolated chromosome 7 abnormalities predict responses to treatment with 5-azacytidine. Leukemia 21(9):1937-1944. doi:10.1038/sj. leu. 2404796

20. Schanz J, Tüchler H, Solé F, Mallo M, Luño E, Cervera J, Grau J, Hildebrandt B, Slovak ML, Ohyashiki K, Steidl C, Fonatsch C, Pfeilstöcker M, Nösslinger T, Valent P, Giagounidis A, Aul C, Lübbert M, Stauder R, Krieger O, Le Beau MM, Bennett JM, Greenberg P, Germing U, Haase D (2013) Monosomal karyotype in MDS: explaining the poor prognosis? Leukemia 27(10):19881995. doi: $10.1038 /$ leu.2013.187

21. Valcarcel D, Adema V, Sole F, Ortega M, Nomdedeu B, Sanz G, Luno E, Canizo C, de la Serna J, Ardanaz M, Marco V, Collado R, Grau J, Montoro J, Mallo M, Vallespi T (2013) Complex, not monosomal, karyotype is the cytogenetic marker of poorest prognosis in patients with primary myelodysplastic syndrome. J Clin Oncol 31(7):916-922. doi:10.1200/jco.2012.41.6073

22. Becker H, Suciu S, Rüter BH, Platzbecker U, Giagounidis A, Selleslag D, Labar B, Germing U, Salih HR, Muus P, Pflüger KH, Hagemeijer A, Schaefer HE, Fiaccadori V, Baron F, Ganser A, Aul C, de Witte T, Wijermans PW, Lübbert M (2015) Decitabine versus best supportive care in older patients with refractory anemia with excess blasts in transformation (RAEBt) - results of a subgroup analysis of the randomized phase III study 06011 of the EORTC Leukemia Cooperative Group and German MDS Study Group (GMDSSG). Ann Hematol 94(12):2003-2013. doi:10. 1007/s00277-015-2489-6
23. Breems DA, Van Putten WLJ, De Greef GE, Van Zelderen-Bhola SL, Gerssen-Schoorl KBJ, Mellink CHM, Nieuwint A, Jotterand M, Hagemeijer A, Beverloo HB, Löwenberg B (2008) Monosomal karyotype in acute myeloid leukemia: a better indicator of poor prognosis than a complex karyotype. J Clin Oncol 26(29):47914797. doi:10.1200/jco.2008.16.0259

24. Cheson BD, Greenberg PL, Bennett JM, Lowenberg B, Wijermans PW, Nimer SD, Pinto A, Beran M, de Witte TM, Stone RM, Mittelman M, Sanz GF, Gore SD, Schiffer CA, Kantarjian H (2006) Clinical application and proposal for modification of the International Working Group (IWG) response criteria in myelodysplasia. Blood 108(2):419-425. doi:10.1182/blood-200510-4149

25. Cheson BD, Bennett JM, Kantarjian H, Pinto A, Schiffer CA, Nimer SD, Löwenberg B, Beran M, de Witte TM, Stone RM, Mittelman M, Sanz GF, Wijermans PW, Gore S, Greenberg PL, World Health Organization (WHO) international working group (2000) Report of an international working group to standardize response criteria for myelodysplastic syndromes. Blood 96(12): $3671-3674$

26. Wijermans PW, Krulder JWM, Huijgens PC, Neve P (1997) Continuous infusion of low-dose 5 -aza-2'-deoxycytidine in elderly patients with high-risk myelodysplastic syndrome. Leukemia 11(1):1-5. doi:10.1038/sj.leu.2400526

27. Wijermans P, Lübbert M, Verhoef G, Bosly A, Ravoet C, Andre M, Ferrant A (2000) Low-dose 5-aza-2'-deoxycytidine, a DNA hypomethylating agent, for the treatment of high-risk myelodysplastic syndrome: a multicenter phase II study in elderly patients. J Clin Oncol Off J Am Soc Clin Oncol 18(5):956-962

28. Kantarjian H, Issa J-PJ, Rosenfeld CS, Bennett JM, Albitar M, DiPersio J, Klimek V, Slack J, de Castro C, Ravandi F, Helmer R, Shen L, Nimer SD, Leavitt R, Raza A, Saba H (2006) Decitabine improves patient outcomes in myelodysplastic syndromes. Cancer 106(8):1794-1803. doi:10.1002/cncr.21792

29. Oosterveld M, Suciu S, Muus P, Germing U, Delforge M, Belhabri A, Aul C, Selleslag D, Ferrant A, Marie JP, Amadori S, Jehn U, Mandelli F, Hess U, Hellström-Lindberg E, Cakmak-Wollgast S, Vignetti M, Labar B, Willemze R, de Witte T (2015) Specific scoring systems to predict survival of patients with high-risk myelodysplastic syndrome (MDS) and de novo acute myeloid leukemia (AML) after intensive antileukemic treatment based on results of the EORTC-GIMEMA AML-10 and intergroup CRIANT studies. Ann Hematol 94(1):23-34. doi:10.1007/s00277-014-2177-y

30. Hwang KL, Song MK, Shin HJ, Na HJ, Shin DH, Kim JK, Moon JH, Ahn JS, Song IC, Hong J, Lee GW, Chung JS (2014) Monosomal and complex karyotypes as prognostic parameters in patients with international prognostic scoring system higher risk myelodysplastic syndrome treated with azacitidine. Blood Res 49(4):234-240. doi:10.5045/br.2014.49.4.234

31. Pleyer L, Burgstaller S, Girschikofsky M, Linkesch W, Stauder R, Pfeilstocker M, Schreder M, Tinchon C, Sliwa T, Lang A, Sperr WR, Krippl P, Geissler D, Voskova D, Schlick K, Thaler J, Machherndl-Spandl S, Theiler G, Eckmüllner O, Greil R (2014) Azacitidine in 302 patients with WHO-defined acute myeloid leukemia: results from the Austrian azacitidine registry of the AGMT-study group. Ann Hematol 93(11):1825-1838. doi:10.1007/s00277-0142126-9 